\title{
Coatings Industry under Pressure from Developments in the Raw Materials Market
}

\author{
The European paint, printing inks and artists' colors industry is under increased pressure due to \\ rising raw material prices. A complex combination of demand, capacity issues and a shortage of \\ transportation resources for key raw materials is increasing uncertainty in the supply chain.
}

After a year marked by the COVID-19 pandemic, the paints, inks and artists' colors industry is once again facing serious challenges in 2021 due to the rise in raw material prices. There are several reasons for the increase, including the growth in demand for raw materials caused by the anticipated economic recovery, a shortage of raw materials as a result of bad weather conditions and the closure of several plants, which has led suppliers of raw materials to invoke force majeure. In addition, transportation costs are on the rise following the sharp increase in oil prices.

\section{Cost drivers}

"The burden on the industry is immense, because raw materials account for more than half of its costs. Since January last year, the price of key components such as epoxy resins has risen by $60 \%$ in Europe. The situation is similar for solvents, with the cost of acetone and n-butyl acetate alone rising by $123 \%$ and $91 \%$ respectively."
The current situation is caused mainly by events in Europe and Asia and, in particular, the unexpectedly rapid V-shaped recovery in China which is fueling demand for essential raw materials. In addition to epoxy resins, the list of petrochemical raw materials that are in demand includes polyester resins, polypropylene glycols, acrylic acids, acrylic resins, UV resins, polyurethane resins and solvents. Alongside petrochemical raw materials, pigment raw materials (including titanium dioxide and red and yellow iron oxide) have also seen sharp increases in costs throughout the world. The key drivers of these increases include high levels of demand across all industries, greater domestic supply requirements in producing countries, generic supply and demand imbalances and higher pigment component costs.

The situation has been exacerbated by capacity issues. Disruptions at producers in Asia and Europe - either due to factory closures or plant accidents - have significantly reduced supplies. Another cost fac-

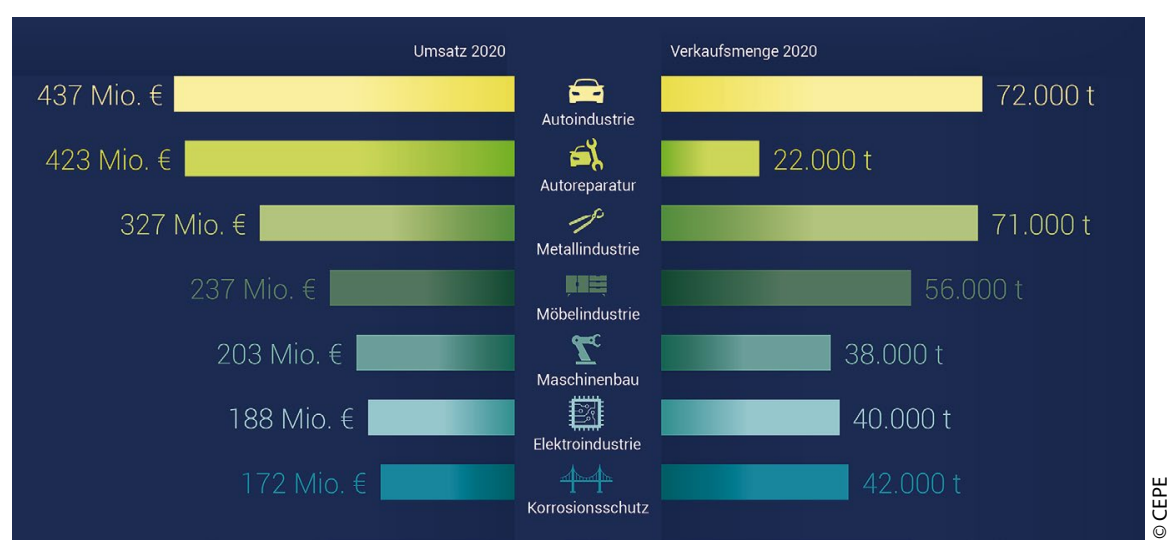

Coatings for industrial applications in Germany. In 2020, 341,000 tons of coatings worth two billion euros were sold on the German market in the seven largest customer sectors. tor is the shortage of transportation. The COVID-19 pandemic has led to erratic demands on international trade which have affected shipping container movements. The current global shortage of containers in the right places has caused a considerable increase in transportation costs: prices of containers between China and Europe have risen by more than $400 \%$ since Q4 2020.

\section{Call for a strong chemical industry in Europe}

While the coatings industry seeks to cope as far as possible with the current uncertainties, world market pressure should give European decision-makers pause for thought. "Increased sustainability is undeniably the way forward, but global competition should not be ignored in the measures that make up the EU Green Deal. It is essential for Europe to have a strong chemicals industry with factories based in Europe in order to be more self-sufficient, otherwise the European economy as a whole will be under threat," concluded André Vieira de Castro.

\section{Contact}

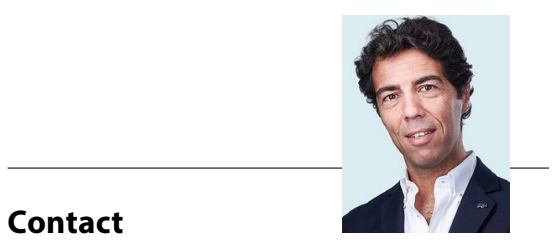

CEPE European Council of the Paint, Printing Ink, and Artist's Colours Industry

Brussels (Belgium)

secretariat@cepe.org

www.cepe.org 


\section{YOUR INDUSTRIAL COATING EQUIPMENT CATALOGUE}

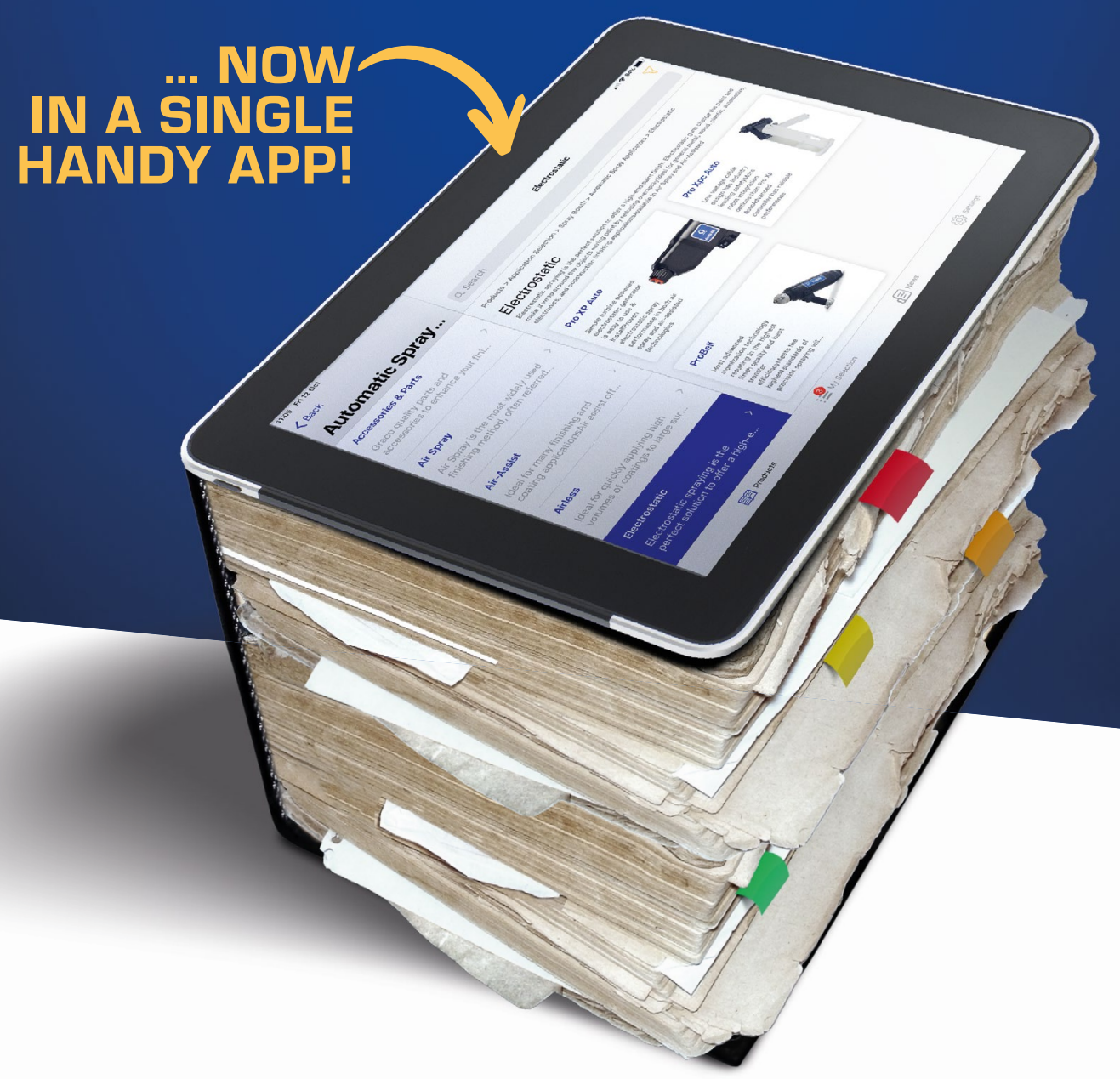

WORK MORE EFFICIENTLY WITH THE INDUSTRIAL COATING EQUIPMENT APP

> Search over 3,000 products

> Quickly scroll through pumps, systems, guns, related accessories ánd parts

> Find part number, description, technical specifications, manuals, ... and more!

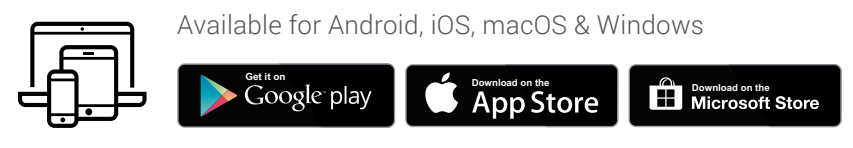

